\title{
PENGARUH KEPEMIMPINAN DAN SUPERVISION TERHADAP KINERJA GURU SEKOLAH MENENGAH ATAS (SMA) NEGERI KABUPATEN DOGIAYI PAPUA
}

\begin{abstract}
Adolvina Tebai*
Abstract: The purpose of this research is to know the effect of leadership and supervision toward teacher's job performance senior high school at regency of Dogiyai Papua. The research was conducted using survey method with quantitative approach and path analysis technique. The population of this research is 75 teachers. Research samples selected as much as 63 teachers using simple random sampling technique. The data obtained through questionnaires and analyzed using path analysis techniques. Based on the results of data analysis in this research it is concluded: (1) the leadership have positive direct effect to job performance; (2) the supervision have positive direct effect to job performance; (3) the leadership have positive direct effect to supervision. The job performance can be improved through improvement of of leadership and supervision.
\end{abstract}

Keywords: Job Performance, Leadership and Supervision

\section{PENDAHULUAN}

Sekolah dalam mencapai tujuannya,yaitu output,seringkali diperhadapkan pada hambatan-hambatan berupa rendahnya kinerja guru,yang ditandai dengan masih ada beberapa sekolah jumlah guru yang mengajar sangat sedikit (tidak sesuai dengan jumlah jam mengajar normalnya), efektifitas, efisiensi, dan standardisasi pendidikan yang masih kurang dioptimalkan, masih ada guru yang kurang terlibat dalam kegiatan sekolah. Lebih jauh dijelaskan bahwa dalam menjalankan tugasnya sebagai pengawas masih banyak menghadapi tantangan di lapangan misalnya masih adanya kepala sekolah yang memiliki kepemimpinan yang masih rendah, misalnya sulit mengambil keputusan, acuh tak acuh dengan permasalahan yang ada, kurang memotivasi para guru dalam meningkatkan kualitas diri atau pembelajaran, serta masih banyak guru yang tidak mempersiapkan diri dengan baik sebelum mengajar. Hal ini sejalan dengan yang dinyatakan oleh Newstrom (2002:163), "leadership is the process of influencing and supporting others to work enthusiastically toward achieving objectives. It is critical factor that helps and individual or a group identify its goal and then motivates and assist in achieving the stated goals. the definition are influence/support, voluntary effort, and a goal achievement".

Lebih lanjut oleh Gary Yukl (2012:444) bahwa, "performance orientation has implication for leadership, because some types of leadership behavior are more relevan for improving performance and efficiency. Examples include setting chellenging goals or standards, developving action plan with schedules and deadlines, expressing confidence that

* Guru SMA Negeri 2 Kabupaten Dogiyai Papua 
subordinates can improve performance, developing job relevan skills in sub ordinates, encouraning and providing praise and reward for achievements".

Menurut Laurie. J Mullins (2005:282), "it is important that there regular, reutine discussions, within supervision about the factor tahat effect performance, then, when performance concern emerge, both supervisior and supervisee will have a head start in unpicking what is contributing to the performance issue. that does not mean that working with the issue will not be challenging, there is unlikely to be one simple explanation, but rather a combination of casual factor stemming from a range of concerns are emerging is fundamental to being able to manage them effectively". Sedangkan menurut Edwin Leonard Jr (2009:49) bahwa, "those hold supervisory positions signivicantly influence the effectiveness with which people work together and use resource attain goals. In short, the managerial role of a supervisor is to make sure that assigned task are accomplished with and through the help of employee". Maka dari itu peneliti ingin mengkaji secara ilmiah apakah kepemimpinan dan supervisi berpengaruh terhadap kinerja guru.

\section{Kinerja}

Gibson et. al (2012:374), mendefinisikan kinerja dengan, "job performance is such as quality, efficiency, and other criteria of effectiveness". Kinerja adalah hasil dari pekerjaan yang berhubungan dengan tujuan organisasi seperti kualitas, efisiensi, dan kriteria efektivitas lainnya. Menurut Jason A. Colquitt, Jefferey a Lepine And Michael J. Wesson (2011:35), mendefinisikan bahwa, "job performance is formally defined as they value of the set of employee behavior that contribute, ether positively or negatively to organizational gola accomplishment". Kinerja secara formal di definisikan sebagai seperangkat nilai perilaku yang memiliki kontribusi baik secara positif maupun secara negatif untuk mencapai tujuan organisasi.

Hal yang senada di ungkapakan juga oleh Laurie J. Mullins (2005:700) bahwa, "the relationship between job satisfaction and performance is an issue of continuing relations approach is that satisfaction leads to performance". Terdapat korelasi antara kinerja dengan kepuasan kerja adalah masalah yang terus menjadi perdebatan dan kontraversial. Colquitt (2011:39), juga menegaskan pada perilaku kinerja (tugas dan tanggung jawab) yang merupakan inti dari pekerjaan. Seperti yang dijelaskan bahwa, "that description will focus on task performance behaviors the tasks, duties and responsibilities that are a core part of the job. Put differently; task performance is the set of explicit obligation that an employee must fulfill receive compensation and continued employment". Kinerja merupakan perilaku yang menunjukkan kompetensi yang relevan dengan tugas secara nyata dan gambaran perilaku tersebut difokuskan pada konteks pekerjaan yaitu perilaku yang artikulasikan untuk memenuhi kebutuhan organisasi yang diinginkan.

Robbins dan Judge (2011:599), mendeskripskan kinerja berkembang menjadi 3 jenis perilaku yang dapat menentukan kualitas kinerja seseorang sebagai berikut:

a) Task performance. Performance the duties and responsibilities that contribute to the production of a good or service to administrative task. This includes most of the task in a conventional job description. 
b) Citizenship. Ection that contribute to the psychological environment of the organization, such as helping others when not required, supporting organizational objectives, treating co-workers with respect, making constructive suggestion and saying positive things about a work place.

c) Counter productivity. Action that actively damage the organization. These behavior include strealing, damaging company property, behaving aggressively toward coworkers and avoidable absences.

Tiga jenis perilaku yaitu:

a) Task performance, kinerja yang berorientasi pada tugas. Pelaksanaan tugas dan tanggung jawab sebagai kontribusi terhadap barang atau jasa dalam tugas administrasi, hal ini termasuk deskripsi [ekerjaan yang telah disepakati;

b) Citizenship, tindakan kontribusi kepada lingkungan organisasi secara psikologis seperti menawarkan bantuan, mendukung tujuan organisasi, berperilaku terhadap sesama rekan kerja dengan sikap hormat, saran yang membangun dan mengungkapkan hal- hal positif tentang tempat kerja;

c) Counterproductivity. Tindakan yang secara aktif meruusak organisasi. Perilaku yang menunjukkan hal ini termasuk mencuri, merusak barang milik perusahan, bertindak agresif terhadap rekan kerja.

Pendapat di atas dapat dideskripsikan, 1) kinerja tugas (task performance) meliputi perilaku karyawan yang secara langsung terlibat di dalam transformasi sumber daya organisasi kedalam hasil produksi organisasi baik barang atau jasa, 2) perilaku kesetiaan (citizenships behavior) adalah aktivitas karyawan secara sukarela tidak untuk diberi penghargaan tetapi memberikan kontribusi kepada organisasi dengan meningkatkan kualitas kerja di tempat kerjanya, dan 3) perilaku kontra produktif (counter productive behavior) adalah perilaku karyawan yang dengan sengaja menghambat pemenuhan tujuan organisasi yang memberikan kontribusi negatif pada organisasi.

Mc Clelland (2005:489), dalam Mullins menyarankan terdapat 4 langkah dalam meningkatkan kinerja, yaitu:

Four steps in attempting to develop achievement drive:

a. Striving to attain feedback on performance. reinforcement of success serve to strengthen the desire to attain higher performance.

b. Developing models of achievement by seeking to emulate people who have pwrformed to well.

c. Attempting to modify their self image and to see them selves as needing challenges and success.

d. Controlling day-dreaming and thingking about them selves in more positive terms.

Empat langkah meningkatkat kinerja yaitu: a) Melakukan usaha perbaikan

dari hasil umpan balik terhadap kinerja, b) mengembangkan model-model keberhasilan dengan mencari oorang lain memiliki kinerja baik, c) mencoba untuk memodifikasi citra diri mereka sendiri sebagai individu yang memebutuhkan tantanga dan sukses, d) mengendalikan impian harian dan berpikir tentang diri mereka sendiri dalam arah yang positif. 
Dari hasil yang telah dideskripsian oleh Gibson di atas dapat disimpulkan bahwa: Pengukuran kinerja memerlukan alat ukur yang tepat. Dasar filosofi yang dapat dipakai dalam merencanakan sistem pengukuran prestasi harus disesuaikan dengan strategi perusahaan, tujuan dan struktur organisasi perusahaan. Sistem pengukuran kinerja yang efektif adalah sistem pengukuran yang dapat memudahkan manajemen untuk melaksanakan proses pengendalian dan memberikan motivasi kepada manajemen untuk memperbaiki dan meningkatkan kinerjanya agar ada kontribusi yang diperoleh oleh suatu institusi.

Berdasarkan uraian mengenai kinerja di atas, dapat disintesiskan bahwa kinerja adalah keberhasilan yang dicapai seseorang dalam melaksanakan tugastugas atau pekerjaan sesuai dengan standar dan kriteria yang di tetapkan, dengan indikator: Mutu kerja, kuantitas kerja ,ketangguhan dan sikap.

\section{Kepemimpinan}

Mullins (2005:281) menjelaskan bahwa, "there are many ways of looking at leadership and many interpretations of its meaning. Leadrship might be interpreted in simple terms, such as getting others to follow or getting people to do things willingly; or interpreted more apecifically, for example as authority in decision making. Menurut Mullins". Kepemimpinan dapat ditafsirkan secara sederhana dan secara spesifik. Secara sederhana, kepemimpinan adalah upaya untuk memperoleh pengikut atau membuat orang lain untuk melakukan hal-hal secara sukarela. Lebih spesifik, kepemimpinan didefinisikan sebagai pengguna wewenang dalam pengambilan keputusan. Artinya bahwa, kemampuan untuk mengambil keputusan sesuai dengan nilai dan norma yang berlaku dan kekuasaan yang syah untuk melaksanakan peranan sesuai dengan jabatan untuk mewujudkan harapan-harapan selaras dengan lingkungannya yang merupakan wahana untuk memasyarakatkan nilai-nilai dan norma-norma dalam suatu lingkungan, kemudian harus bijak dalam mengambil wewenang yang dimiliki oleh seorang leader, jangan sampai merugikan orang lain akan tetapi menguntungkan diri sendiri.

Colquitt (2011:474) menjelaskan bahwa, leadership defined as the use of power and influence to direct the activities of followers toward goal achievement. That direction can affect followers interpretation of events, the organizational of their work activities, their commitment to key goals, their relationship with other followers, opr their access to cooperation and support from others work unit. Pendapat Colquitt dapat di artikan bahwa, Kekuasaan dapat di artikan sebagai kemampuan untuk mempengaruhi orang lain dalam mencapai sesuatu dengan cara yang diinginkan. Kekuasaan tak luput hubungannya dengan organisasi dan kepemimpinan. Dalam suatu organisasi sebagai wadah yang memiliki struktur, dimana terdapat seorang pemimpin sebagai atasan dan orang yang dipimpin sebagai bawahannya pasti terdapat didalamnya kekuasaan serta kepemimpinan.

Gary Yukl (2012:20), mendefinisikan kepemimpinan berdasarkan dimensi perilaku. Bahwa, "leadership has been defined in term of traits, behaviors, influence, interaction patterns, role relationship, and occupationol an administrative position". 
Kepemimpinan didefinisikan dalam sifat, perilaku, pengaruh, pola interaksi, hubungan peran.

berdasarkan berbagai pendapat para ahli yang telah di sebutkan di atas, dapat di sintesiskan bahwa, Kepemimpinan adalah, Proses mempengaruhi dari pemimpin kepada pengikutnya dalam upaya mencapai tujuan Organisasi, dengan indikator: mengarahkan, memberikan inspirasi, melibatkan atau melakukan kerja sama.

\section{Supervisi}

Menurut Sergiovani dan Staraat dalam Mulyasa (2004:111) mengatakan bahwa, "supervision is a process designed to help teacher and supervisor learn more about their practice, to better able to use their knoledge and skills to better serve parents and schools and to make the schools a more effective learning community". Kutipan di atas menunjukkan bahwa supervisi merupakan suatu proses yang di rancang secara khusus untuk membantu para guru dan supervisor dalam mempelajari tugas seharihari di sekolah, agar dapat menggunakan pengetahuan dan kemampuan untuk memberikan layanan yang lebih abik kepada orang tua peserta didik dan sekolah, serta berupaya menjadikan sekolah sebagai masyarakat belajar yang lebih efektif.

Rue Byars berpendapat bahwa (2010:03), "supervision is the first level of management in an organizational and is concerned with encouraging the members of a work unit to contribute positively toward accomplishing the organization's goals and objectives. This means that the supervisor does not do the operative work but sees that it is accomplished through the efforts of others". Supervisi adalah tingkat pertama dari manajemen dalam suatu organisasi dan berkaitan erat dengan mendorong para anggota unit kerja untuk berkontribusi positif terhadap unit pencapaian tujuan dan sasaran organisasi". Ini berarti bahwa supervise tidak melakukan pekerjaan operasi tetapi melihat bahwa itu dicapai melalui usaha orang lain.

Selanjutnya V. G. Kondalkar (2007:90), menjelaskan bahwa, "supervision is one of the moderate factors, which affect job satisfaction. Qualified supervisors should be avalaible for advice, guidance and problem solving. Supervision should be placed close to the place of work and should be avalaible. They should take personal interest in the affairs of employees both on value, attitudeand job satisfaction personal and official level. Supervisi adalah salah satu factor moderat, yang mempengaruhi kepuasan kerja. Supervisor yang berkualitas seharusnya mampu memberikan saran, petunjuk dan mampu memecahkan masalah. Supervisor seharusnya ditempatkan di tempat bekerja dan harus terus tersedia. Mereka seharusnya memiliki minat dalam berhubungan dengan para karyawan baik pada nilai- nilai, sikap dan kepuasan bekerja baik dalam tingkatan personal atau resmi.

Mukhneri Mukhtar (2011:70-71) mengungkapkan bahwa, Supervise pendidikan adalah, segala usaha yang dilakukan oleh kepala sekolah dalam rangka pemberian pengarahan, bantuan dan bimbingan kepada guru-guru dalam memperbaiki dan meningkatkan proses belajar mengajar disekolah dengan tujuan perbaikan system instruksional, system belajar dan kurikulum pengajaran di sekolah. Supervisi pendidikan mengandung beberapa unsur diantaranya: (1) Proses 
pengarahan, bantuan atau pertolongan dari pihak atasan atau pihak yang lebih memahami, (2) memeberikan nasehat kepada guru dan personalia sekolah lainnya yang berhubungan dengan pelaksanaan kegiatan pembelajaran untuk para siswa sebagai pihak yang diberi pertolongan, (3) perilaku guru dalam pelaksanaan proses belajar mengajar atau situasi belajar dalam suatu lembaga persekolahan.

Berdasarkan pendapat para ahli di atas, maka pengertian supervisi dapat di sintesiskan bahwa, Supervisi adalah: Usaha yang dilakukan oleh kepala sekolah dalam rangka pemberian pengarahan, bantuan dan bimbingan kepada guru- guru dalam memperbaiki dan meningkatkan proses belajar- mengajar di sekolah dengan tujuan perbaikan system instruksional, system belajar dan kurikulum pengajaran di sekolah. Dengan indikator: membimbing, memotivasi dan mengarahkan.

\section{METODE}

Penelitian ini dilaksanakan pada guru Sekolah Menengah Atas (SMA) Negeri Kabupaten Dogiyai Papua. dilaksanakan selama 3 (tiga) bulan. Metode yang digunakan dalam penelitian ini adalah survey dengan menggunakan teknik kausal. Populasi adalah guru Sekolah Menengah Atas (SMA) Negeri Kabupaten Dogiyai Papua yang berjumlah 75 guru dengan jumlah sampel sebanyak 63 guru. Data yang dikumpulkan dalam penelitian dijaring melalui kuesioner yang berupa skala penilaian (rating scale) dengan sebaran skor antara 1 sampai dengan 5.

Setelah dilakukan analisis deskriptif dilanjutkan dengan uji persyaratan analisis berupa uji normalitas, uji linearitas data dan keberartian regresi, dilakukan uji hipotesis dengan menggunakan teknik analisis jalur (path analysis).

\section{HASIL DAN PEMBAHASAN}

\section{Pengaruh Kepemimpinan terhadap Kinerja}

Hasil penelitan ini menunjukkan bahwa Kepemimpinan memberikan pengaruh positif secara langsung terhadap kinerja. Besarnya pengaruh tersebut ditunjukkan oleh koefisien korelasi 0,620 dan koefisien jalur 0,501. Hal ini menujukkan bahwa Kepemimpinan dapat meningkatkan kinerja guru.

Hasil penelitian ini sesuai dengan yang di ungkapkan oleh Newstrom (2002:163) bahwa, leadership is the process of influencing and supporting others to work enthusiastically toward achieving objectives. It is critical factor that helps and individual or a group identify its goal and then motivates and assist in achieving the stated goals. The definition are influence/support, voluntary effort, and a goal achievement. Kepemimpinan adalah proses mempengaruhi dan mendukung orang lain untuk bekerja dengan antusias untuk mencapai tujuan. fakta tersebut menjadi faktor penting yang membantu individu atau kelompok dalam mengidentifikiasi tujuan, memotifasi dan membantu pencapaian tujuan yang di tetapkan. kepemimpinan menjadi atribut yang cukup penting bagi peningkatan motivasi dan kinerja karyawan

Menurut Gary Yukl (2012:444) performance orientation has implication for leadership, because some types of leadership behavior are more relevan for improving performance and efficiency. Examples include setting chellenging goals or standards, 
developving action plan with schedules and deadlines, expressing confidence that subordinates can improve performance, developing job relevan skills in sub ordinates, encouraning and providing praise and reward for achievements. Kepemimpinan memiliki dampak yang sangat besar terhadap kinerja karena sangat relevan hubungan antara keduanya yaitu antara kepemimpinan dan kinerja. Contohnya, dengan menerapakan suatu jadwal tertertentu dalam mengemban tugas dan tanggung jawab seorang pemimpin di butuhkan keahlian, ketelitian kejelian dan keuletan, aplikasi dari tanggung jawab seseorang sebagaii pemimpin, karena akan terlihat atau nampak pada Kinerjanya.

Mullins (2005:28) menjelaskan bahwa, good leadership involves the effective process of delegation and emporwerment. leadership is a dynamic prosess. the leader follower relationship is reciprocal and effective leadership is a two way process which influences both individual and organizational performance. Kepemimpinan yang baik merupakan proses yang efektif dalam pendelegasian dan pemberdayaan. hubungan antara pemimpin dan pengikut terjadi secara resiprokal dan kepemimpinan yang efektif terjadi melalui dua proses yang mempengaruhi kinerja individu dan kinerja oraganisasi.

Merujuk dari teori tersebut dengan demikian terdapat pengaruh langsung positif Kepemimpinan terhadap kinerja guru. Dengan kata lain semakin tinggi Kepemimpinan kepala sekolah maka semakin tinggi kinerja guru

\section{Pengaruh supervisi terhadap kinerja}

Hasil penelitan ini menunjukkan bahwa Lingkungan Kerja memberikan pengaruh positif secara langsung terhadap komitmen organisasi. Besarnya pengaruh tersebut ditunjukkan oleh koefisien korelasi 0,498 dan koefisien jalur 0,297.

Hasil penelitian ini sejalan dengan pendapat Menurut Laurie. J Mullins (2005:282) Bahwa,"it is important that there regular, reutine discussions, within supervision about the factor tahat effect performance, then, when performance concern emerge, both supervisior and supervisee will have a head start in unpicking what is contributing to the performance issue. that does not mean that working with the issue will not be challenging, there is unlikely to be one simple explanation, but rather a combination of casual factor stemming from a range of concerns are emerging is fundamental to being able to manage them effectively". Penting untuk diadakan diskusi secara rutin mengenai factor- factor yang mempengaruhi kinerja dalam pengawasan, yang nantinya, ketika

kekwatiran kinerja muncul, pengawas dan karyawan akan memiliki gambaran untuk menghindari hal-hal yang dapat menghambat kinerja. itu tidak berarti bahwa kinerja dengan masalah ini tidak akan menantang, ada mungkin merasa tidak nyaman untuk salah satu pihak, dan tidak mungkin menjadi salah satu penjelasan sederhana, melainkan kombinasi dari factor kausal yang berasal dari berbagai sumber mencoba untuk memahami mengapa masalah yang mencul sangat penting untuk mampu mengelola secara efektif.

Jane Wonnacott (2012:147) berpendapat, bahwa, it is important that there regular, routine disscussions, within supervision about the factor that effect performance, 
then when performance concern emerge, both supervisor and supervisee will have a head start in unpicking what is contributing tothe performance issue. That does not mean that working with the issue will not be challenging, there is unlikely to be one simple explanation, but rather a combination of casual factor stemming from a range of sources. Trying to understanding why concerns are emerging is fundamental to being able to manage affectively. Penting untuk di adakan diskusi secara rutin mengenai faktor-faktor yang mempengaruhi kinerja dalam pengawasan, yang natinya, ketika kekawatiran kinerja muncul, baik pengawas dan karyawan akan memiliki gambaran untu meghindarai hal-hal yang dapat mengahambat kinerja. Itu tidak berrta bahwa bekerja dengan masalah ini tidak akan menantang, ada yang mungkin merasa tidak nyaman untuk aalah satu pihak, dan ada yang tidak mungkin menjadi penjelasan sederhana, melainkan kombinasi dari faktor kasual yang berasal dari berbagai sumber.

Menurut Ingersoll R. M (2004:641), Job satisfaction is particularly important in a tecaher's perception of the sshool"s culture and their influence over a school"s policy. The supervision a teacher receives affects the performance and satisfaction of teachers. Teachers are more committed and work harder when they are supported by the schools administration. Kepusan kerja sangat penting dalam persepsi guru tentang budaya sekolah dan pengaruh mereka atas kebijakan sekolah. Pengawasan guru memepengaruhi kinerja dan kepuasan guru.Guru lebih berkomitmen dan bekerja lebih keras ketika mereka di dukung oleh administrasi sekolah.

Merujuk dari beberapa teori di atas, dapat disimpulkan bahwa, terdapat pengaruh langsung positif supervisi terhadap kinerja guru. Dengan kata lain semakin tinggi supervisi kepala sekolah maka semakin tinggi kinerja guru.

\section{Pengaruh Kepemimpinan terhadap Supervisi}

Hasil penelitan ini menunjukkan bahwa Kepemimpinan memberikan pengaruh positif secara langsung terhadap pembelajaran oraganisasi. Besarnya pengaruh tersebut ditunjukkan oleh koefisien korelasi 0,401 dan koefisien jalur 0,401. Hasil penelitian ini bertepatan dengan pendapat Edwin Leonard Jr (2009:49) bahwa," those hold supervisory positions signivicantly influence the effectiveness with which people work together and use resource attain goals. In short, the managerial role of a supervisor is to make sure that assigned task are accomplished with and through the help of employee". Posisi pengawas dalam berkedudukan sebagai supervisor atau seorang pemimpin memegang peranan penting, karena sangat berpengaruh dengan tujuan organisasi yang hendak dicapai yaitu dengan mengarahkan dan mensupervisi pegawainya dalam melaksanakan tugas-tugas yang diembani agar mencapai target dan tujuan organisasi secara efektif.

Jake Reynold menjelaskan dalam buku Michael Amstrong (2006:144) bahwa,"improvement and learning are causally related; obtain the will to improve and the process of learning will follow. The experience of work always will provide the richest learning laboratory". Perbaikan dan pembelajaran memiliki hubungan sebab akibat. 
Keinginan untuk melakukan perbaikan maka akan diikuti dengan keinginan untuk belajar. Pengalaman merupakan sumber yang kaya dalam suatu pembelajaran.

Dalam buku Laurie J. Mullins, Herzberg (2005:714) berpendapat, job enrichment arose out of Herzberg's two-factor theory. It attempt to enrich the job by incorporating motivating or growth factor such as increased responsibility and involvement, opportunities for advancement and the sense of achievement. Job enrichment aims to give the person greater autonomy and authority over the planning, execution and control of their own work. It provides greater opportunities for psychological growth. Definisi ini mengandung makna supervisi pekerjaan diinspirasi oleh 2 faktor pendorong motivasi (hygiene/maintenanceand motivator/growth factors). Dalam hal ini yang di bahas adalah mengenai faktor pendorong (motivator/growth factor) yang memberi motivasi dan memperkaya pekerjaan pada anggota organisasi seperti penambahan tanggungjawab, keterlibatan dan memperoleh kesempatan lebih serius mengenai suatu pekerjaan sehingga adanya perasaan sukses dalam diri anggota organisasi. Tujuan dari supervisi adalah untuk memberikan otonomi dan otoritas yang lebih pada perencanaan, pelaksanaan dan pengawasan dari suatu pekerjaan. Selain itu juga memberikan kesempatan lebih besar dari perkembangan kepribadian seseorang.

Menurut Jones and George (2012:333), "the most immediate and potent of a behavior control is direct supervision by managers who actively monitor and observe the behavior of their subordinates". Pengawasan secara langsung adalah suatu tindakan supervisi yang di lakukan oleh seorang manejer yang aktif dan termasuk suatu observasi dari atasan kepada bawahannya.

Merujuk dari teori tersebut dengan demikian terdapat pengaruh langsung positif kepemimpinan terhadap supervisi kepala sekolah kepada guru. Dengan kata lain semakin tinggi kepemimpinan maka semakin tinggi supervisi kepala sekolah terhadap guru.

\section{PENUTUP}

Kesimpulan: (1) Kepemimpinan berpengaruh langsung positif terhadap kinerja guru. Artinya, semakin tinggi tingkat Kepemimpinan kepala sekolah mengakibatkan penigkatan kinerja guru Sekolah Menengah Atas (SMA) Negeri Kabupaten Dogiyai Papua. (2) Supervisi berpengaruh langsung positif terhadap kinerja guru. Artinya, semakin tinggi supervisi kepala sekolah mengakibatkan peningkatan kinerja guru Sekolah Menengah Atas (SMA) Negeri Kabupaten Dogiyai Papua. (3) Kepemimpinan berpengaruh langsung positif terhadap supervisi kepala sekolah terhadap guru. Artinya, semakin tinggi tingkat Kepemimpinan mengakibatkan peningkatan supervisi kepala sekolah terhadap guru Sekolah Menengah Atas (SMA) Negeri Kabupaten Dogiyai Papua.

Saran: saran-saran untuk kepala sekolah. diharapkan dapat meningkatkan Kepemimpinan dengan cara-cara sebagai berikut: (1) kesadaran kepala sekolah dalam melakukan tindakan (conscientiousness), (2)keramahan kepala sekolah dalam 
bersikap, (3) tingkat kenyamanan kepala sekolah dalam bekerja, (4) stabilitas emosional kepala sekolah dalam mengahadapi masalah, (5) kepala sekolah harus terbuka terhadap hal-hal baru.

Kedua, saran untuk kepala sekolah terkait dengan supervisi agar dapat meningkatkan kinerja guru dengan meningkatkan (1) peka terhdapa masalah yang ada, (2) cepat dalam mengambil keputusan(3) manerima masukan dan saran (4) mengontrol guru dengan baik. (5) melaksanakan tugas supervisi sesuai dengan standar operasional.

\section{DAFTAR RUJUKAN}

E. Mulyasa. Menjadi Kepala Sekolah Profesional dalam Konteks Menyukseskan MBS dan KBK. Bandung: PT. Remaja Rosda Karya. 2004.

Edwin C. Leonard Jr, Supervision. South Western: Engage Learning, Edition.

Gary Yukl, Leadership in organization 7th Edition. New Jersey: Prentice Hall, 2012.

James L. Gibson, et. al., Organizations: Behavior, structur, processes. New York: McGraw Hill, 2012.

Jane Wonnacott, Mastering Social Work Supervision. USA: Philadelpia, 2012.

Jasson Colquit A. Jefferey Lepine, and Michael J. Wesson, OrganizationBehavior. New York: McGrow- Hill Compenies. Inc., 2011.

Laurie J. Mullins, Management and Organization Behavior. England: Person Educational Limited, 2005.

Stephen P. Robbins dan Timothi A. Judge, Organizational Behavior.New Jersey: Pearson Educational, Inc, 2011.

Mukhneri Mukhtar, Supervision: Improving Performance and Development Quality in Education. Jakarta: Prodi Manajemen Pendidikan, 2011.

Rue, Byars, Supervision Tenth Edition. United States: McGraw Hill, 2010.

Susan Sulivan dan Jefferey Glans; Foreword by Karen Osterman, Supervision that Improves Teaching and Learning. The United Statesof America: Corwin A Sage Company, 2005.

V. G. Kondalkar, Organizational Behavior. New Delhi: New Age International, 2007. 